\title{
Effectiveness of Roleplay Video Method in Teaching Communication Skills for Undergraduate Medical Students in Pharmacology in Indian Medical School
}

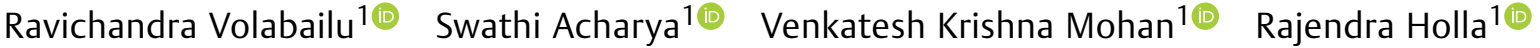 \\ ${ }^{1}$ Department of Pharmacology, K. S. Hegde Medical Academy, Deralakatte, \\ Nitte (Deemed to be University), Mangaluru, Karnataka, India \\ J Health Allied Sci ${ }^{\mathrm{NU}}$ 2022;12:155-161. \\ Address for correspondence Swathi Acharya, MBBS, MD, Department \\ of Pharmacology, K. S. Hegde Medical Academy, Deralakattte, Nitte \\ (Deemed to be University), Mangaluru 575018, Karnataka, India \\ (e-mail: swathiacharya@nitte.edu.in).
}

\begin{abstract}
Keywords

- roleplay

- communication

- pharmacology

- kalamazoo consensus statement

Background Communication is an important skill to be honed and applied by Indian medical graduate, as per revised regulations on Graduate Medical Education 2019. The objective of the present study was to evaluate the effectiveness of roleplay video demonstration in teaching communication skills to students using standard pharmacology drug prescription scenarios.

Materials and Methods In this study, 136 students were divided into three batches, and in each batch, they were paired as a group of one doctor and patient and were asked to perform a roleplay of doctor-patient communication to a standard drug prescription case scenario. Communication skills of the simulated doctor were assessed before and after the administration of standard roleplay video, using modified Kalamazoo consensus statement by both the patient (peer evaluation) and the doctor (self-assessment). The effectiveness of roleplay was evaluated by comparing the total score before and after the roleplay demonstration using the Wilcoxon signed rank test. The difference between the scores of self-evaluation and peer evaluation was tested using Mann-Whitney $\mathrm{U}$ test.

Results The communication skills score of after intervention-before intervention $(p=0.001)$ showed 59 positive ranks and 36.64 mean rank among patient group and 61 positive ranks and 36.74 mean rank among doctors' group, indicating there was a significant improvement in communication.

Conclusion Roleplay video demonstration improved the communication skills of students in the pharmacology practical class session. It helped in the active participation of the students and was appreciated by the majority of the students.
\end{abstract}

\section{Introduction}

Patient-doctor communication is an integral part of clinical practice. A physician obtains information from and shares information with a patient, leading either to a good therapeutic patient-doctor relationship or dissatisfaction on both sides. ${ }^{1}$ Patients with a better understanding of their treating doctors are more likely to acknowledge their
DOI https://doi.org/ $10.1055 / \mathrm{s}-0041-1736283$. ISSN 2582-4287.

\footnotetext{
(c) 2021. Nitte (Deemed to be University). All rights reserved. This is an open access article published by Thieme under the terms of the Creative Commons Attribution-NonDerivative-NonCommercial-License, permitting copying and reproduction so long as the original work is given appropriate credit. Contents may not be used for commercial purposes, or adapted, remixed, transformed or built upon. (https://creativecommons.org/ licenses/by-nc-nd/4.0/)

Thieme Medical and Scientific Publishers Pvt. Ltd., A-12, 2nd Floor, Sector 2, Noida-201301 UP, India
} 
health problems, understand their treatment options, modify their behavior accordingly, and follow their medication schedules. ${ }^{2}$ Studies have shown that medical students who undergo basic communication skills training perform better while communicating with patients. ${ }^{3} \mathrm{~A}$ systematic review of 40 years of published studies confirmed that good doctor-patient communication impacts a range of patient outcomes. ${ }^{4}$ In contrast, deficiencies in communication are associated with medical errors and adverse patient experiences. ${ }^{5}$ Various formal training programs have been created to enhance and measure specific communication skills. However, many of these efforts focus at medical schools and during early postgraduate years and often remain dormant in the academic field. The communication skills of the physician often remain poorly developed, which increases the need for established physicians to become better communicators. ${ }^{6}$ Till recently, training in communication skills was not an integral part of the medical curriculum in India. 7,8

According to the revised regulations on Graduate Medical Education 2019, Indian medical graduates must be able to communicate appropriately and effectively with patients, families, colleagues, and community, making them quality communicators. Early clinical exposure also necessitates precise and formal training of students on the acquisition of communication skills. ${ }^{9}$ A hybrid program that uses different instructional strategies to accommodate different learning styles is desirable in training. Didactic sessions supplemented by small group discussions with essential instructions are essential to highlight skills that the medical student needs to acquire to be a communicator. Students need an environment where their beliefs, attitudes, and behaviors can be observed, analyzed, and challenged, which can be achieved in a skill laboratory. Practicing specific communication skills like explaining the drug medications on peers or standardized patients can be done in these sessions. ${ }^{10}$ In a review by Bokken et al, the use of real and simulated patients in undergraduate medical education was mentioned as an indispensable component. ${ }^{11}$

The Association of American Medical Colleges, Cincinnati, the expert committee, identified core seven components of fundamentals of encounters between clinicians and patients. These are as follows: build the relationship, open the discussion, gather information, understand the patient's perspective, share information, reach an agreement on problems and plans, and provide closure, which can be taught to the students during the communication training program using the Calgary-Cambridge patient interview model framework. $^{12}$

In this context, the present study was planned to evaluate the effectiveness of the roleplay video demonstration to improve the communications skills of MBBS II students in simulated doctor-standardized patient interactions in pharmacology using clinical case scenarios (-Video 1).

\section{Video 1}

Standard doctor-patient communication of urinary tract infection prescription scenario. Online content including video sequences viewable at: https://www. thieme-connect.com/products/ejournals/html/ $10.1055 / \mathrm{s}-0041-1736283$.

\section{Materials and Methods}

This interventional study was conducted in the Department of Pharmacology of a medical college in south India. After obtaining approval from the Institutional Ethics Committee (INST.EC/EC/073/2019-20), the study was performed in September 2019. The study participants included were the fourthterm medical undergraduates who consented to participate in the study. A total of 147 students were enrolled in the study, and among these, 136 students participated in the study.

The following steps were followed in inculcating communication skills to the medical students (-Fig. 1 ):

1. A brief lecture highlighting the salient aspects of communication to become a good communicator in the initial half an hour was presented. ${ }^{12}$

2. A handout consisting of a standard clinical prescription scenario both physicians and patients faced was provided to all 136 students. Students were grouped into 68 pairs, with each pair consisting of two students, one acted as a simulated doctor and the other as a patient.

3. Students were asked to do roleplay of the clinical scenario in the form of simulated doctor-patient interaction in groups. The performance of the simulated doctor was evaluated by the simulated patient (peer evaluation) and the simulated doctor himself (self-assessment), using a modified Kalamazoo adapted scale (preactivity score). ${ }^{12}$

4. A roleplay video of the simulated doctor-patient communication of the same scenario enacted by the department's faculty was played for the students' understanding. Students were given enough time and opportunities to ask and clarify any doubts they had after the lectures and demonstrations. Roleplay video was done to avoid any discrepancies in the roleplays for three different batches.

5. Students were asked to repeat the roleplay after reviewing the video and observing the critical areas of communication. Evaluation of the repeat roleplay was done again, using a modified Kalamazoo adapted scale (postactivity score).

6. The feedback about the whole session was taken from the students.

The standard scenario of prescription to an adult female suffering from urinary tract infection (UTI) was used. A checklist to assesses the roleplay of communication of the prescription to the simulated patient was obtained from a modified Kalamazoo adapted scale. 


\section{Total number of students enrolled 147}

\section{T}

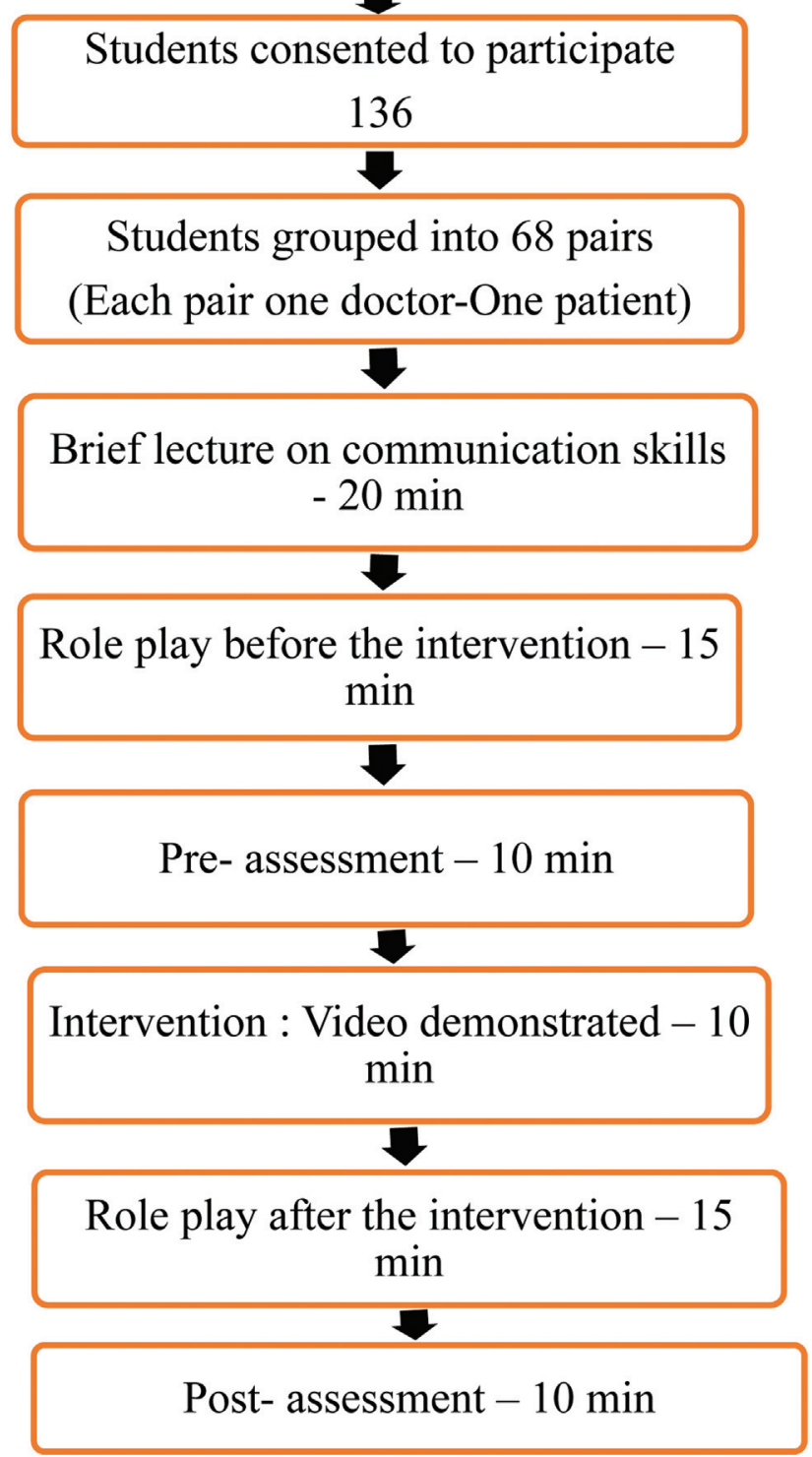

Fig. 1 Flow chart depicting the enrolment of students and Grouping.

\section{Statistical Analysis}

Comparison of preactivity score and postactivity score of "student doctor" (self-evaluation) and "patient" (peer evaluation) groups were made to identify the effectiveness of roleplaying video demonstration. Wilcoxon signed rank test was applied to identify any statistical significance in both groups. Mann-Whitney U test was applied to compare the patients' (peer evaluation) and doctors' perception (selfevaluation) groups.

\section{Results}

A total of 147 students were enrolled in the study. Among these, 136 students participated in the study. These were divided into three batches, grouped into 68 groups of simu- lated doctors and patients. The scores of all the components of the Kalamazoo consensus statement show improvement after the video demonstration compared with before (-Table 1).

The total scores of Kalamazoo consensus statement after intervention-before intervention displayed 59 positive ranks and 36.64 mean rank among patient group and 61 positive ranks and 36.74 mean rank among doctor group. The Wilcoxon signed-rank test showed that the observed difference between both measurements was significant ( $p=0.001$; - Table 2, - Fig. 2).

Mann-Whitney U test displayed a statistically significant higher mean rank observed among patients' perception (mean rank $=77.36$ ) when compared with doctors' perception (mean rank $=60.52$ ) before intervention $(p=0.013)$. The difference in perception among doctors and patients after the intervention was not statistically significant. $(p=0.05)$ (-Table 3, -Fig. 3).

The feedback from students measured on the Likert scale ${ }^{13}$ revealed that most students appreciated the whole exercise. The majority of the students agreed that the initial session of the small lecture helped them to understand the need for communication in a better way (98\%). It helped the students to participate actively in roleplay exercises (95\%), stressed the need for the communication skills' teaching in prescription exercises (89\%), and helped in active learning of the subject (95\%). The feedback on roleplay session suggested that it made the learning session more attractive (93\%), and it was a unique experience compared with regular classes (92\%). As much as $96 \%$ of the students felt this kind of teaching activity would enhance their communication skills in the future, and $86.5 \%$ felt the need for these kinds of session to be conducted regularly. Open-ended questions regarding suggestions for improvement were answered by $50 \%$ of students and included suggestions like introducing different scenarios (9\%) and improved time management for sessions (9\%) (-Table 4).

\section{Discussion}

The present study evaluated the effectiveness of the roleplay in teaching communication skills for undergraduate medical students. The famous Canadian physician, Sir William Osler, known for teaching at the bedside, stated, "A good physician treats the disease, and a great physician treats the patient who has the disease," 14 which highlights the need for a healthy doctor-patient relationship. Communication and trust are the key elements in building a healthy relationship. ${ }^{15}$ It was observed that despite the widespread acknowledgment of the need and significance of effective communication and interpersonal skills, the subject is not emphasized enough in clinical training to date. ${ }^{16,17}$ Medical students usually end up learning the affective domain from their teachers or seniors (a hidden curriculum). A growing number of studies to investigate the most effective teaching communication skills in the medical curriculum have been undertaken in the last few decades. Various teaching methods have been identified to be essential, including patient 
Table 1 Components of Kalamazoo consensus statement and scores

\begin{tabular}{|c|c|c|c|c|}
\hline Sl. no. & Competency & $\begin{array}{l}\text { Possible } \\
\text { maximum } \\
\text { score }\end{array}$ & $\begin{array}{l}\text { Mean } \\
\text { score before } \\
\text { intervention }\end{array}$ & $\begin{array}{l}\text { Mean score } \\
\text { after } \\
\text { intervention }\end{array}$ \\
\hline 1 & $\begin{array}{l}\text { Builds a relationship (includes the following) ( } 4 \text { subcomponents): } \\
\text { Greets and shows interest in the patient and patient's family } \\
\text { Uses words that show care and concern throughout the interview } \\
\text { Uses tone, pace, eye contact, and posture that show care and } \\
\text { concern } \\
\text { Responds explicitly to patient and family statements about } \\
\text { ideas and feelings }\end{array}$ & 20 & 15 & 16.76 \\
\hline 2 & $\begin{array}{l}\text { Opens the discussion (includes the following) (3 subcomponents): } \\
\text { Allows patient and family to complete opening statements } \\
\text { without interruption } \\
\text { Asks "is there anything else?" to elicit full set of concerns } \\
\text { Explains and/or negotiates an agenda for the visit }\end{array}$ & 15 & 11 & 12.4 \\
\hline 3 & $\begin{array}{l}\text { Gathers information (includes the following) (4 subcomponents): } \\
\text { Addresses patient and family statements using open-ended questions. } \\
\text { Clarifies details as necessary with more specific or "yes/no" questions } \\
\text { Summarizes and gives family opportunity to correct or add information } \\
\text { Transitions effectively to additional questions }\end{array}$ & 20 & 14 & 16 \\
\hline 4 & $\begin{array}{l}\text { Understands the patients' perspective (includes the following): } \\
\text { ( } 2 \text { subcomponents): } \\
\text { Asks about life events, circumstances, other people that might affect health } \\
\text { Elicits patient's and family's beliefs, concerns, and expectations } \\
\text { about illness and treatment }\end{array}$ & 10 & 5.9 & 7.68 \\
\hline 5 & $\begin{array}{l}\text { Shares information (includes the following) ( } 3 \text { subcomponents): } \\
\text { Assesses patient's and family's understanding of problems and } \\
\text { desire for more information } \\
\text { Explains using words that family can understand } \\
\text { Asks if family has any questions }\end{array}$ & 15 & 11 & 13 \\
\hline 6 & $\begin{array}{l}\text { Reaches agreement (if new/changed plan) (includes the following) } \\
\text { x0028; } 4 \text { subcomponents): } \\
\text { Includes family in choices and decisions to the extent they desire. } \\
\text { Checks for mutual understanding of diagnostic and/or treatment plans } \\
\text { Asks about acceptability of diagnostic and/or treatment plans } \\
\text { Identifies additional resources as appropriate }\end{array}$ & 20 & 13 & 16 \\
\hline 7 & $\begin{array}{l}\text { Provides closure (includes the following) (5 subcomponents): } \\
\text { Asks if patient and family have questions, concerns or other issues } \\
\text { Summarizes } \\
\text { Clarifies future time when progress will again be discussed } \\
\text { Provides appropriate contact information if interim questions arise } \\
\text { Acknowledges patient and family, and closes interview }\end{array}$ & 25 & 18 & 21 \\
\hline
\end{tabular}

Table 2 Comparison of scores of Kalamazoo consensus scale before and after intervention among patient and doctors' groups

\begin{tabular}{|c|c|c|c|c|c|c|c|}
\hline & & & $n$ & Mean rank & Sum of ranks & Z & $p$-Value \\
\hline \multirow[t]{4}{*}{ Patient } & \multirow[t]{4}{*}{ After-before } & Negative ranks & 8 & 20.44 & 184 & \multirow[t]{4}{*}{-6.045} & \multirow[t]{4}{*}{$0.001^{a}$} \\
\hline & & Positive ranks & 59 & 36.64 & 2162 & & \\
\hline & & Ties & 1 & & & & \\
\hline & & Total & 68 & & & & \\
\hline \multirow[t]{4}{*}{ Doctor } & \multirow[t]{4}{*}{ After-before } & Negative ranks & 7 & 15 & 105 & \multirow[t]{4}{*}{-6.528} & \multirow[t]{4}{*}{$0.001^{\mathrm{a}}$} \\
\hline & & Positive ranks & 61 & 36.74 & 2241 & & \\
\hline & & Ties & 0 & & & & \\
\hline & & Total & 68 & & & & \\
\hline
\end{tabular}

${ }^{\text {a }}$ Statistical significance set at 0.05 (Wilcoxon signed-rank test). 


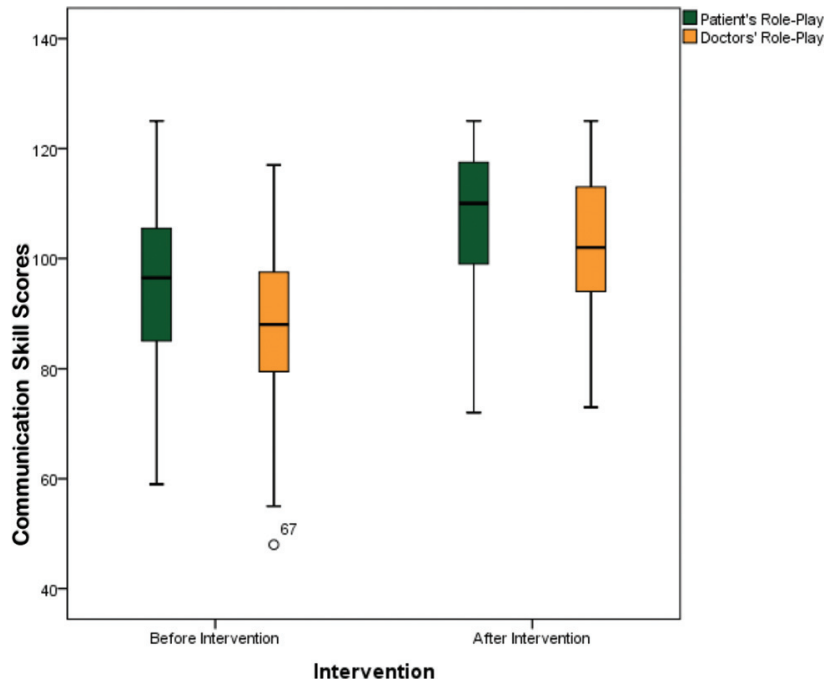

Fig. 2 Showing the distribution of communication skill scores in patient and doctors group before and after the intervention.

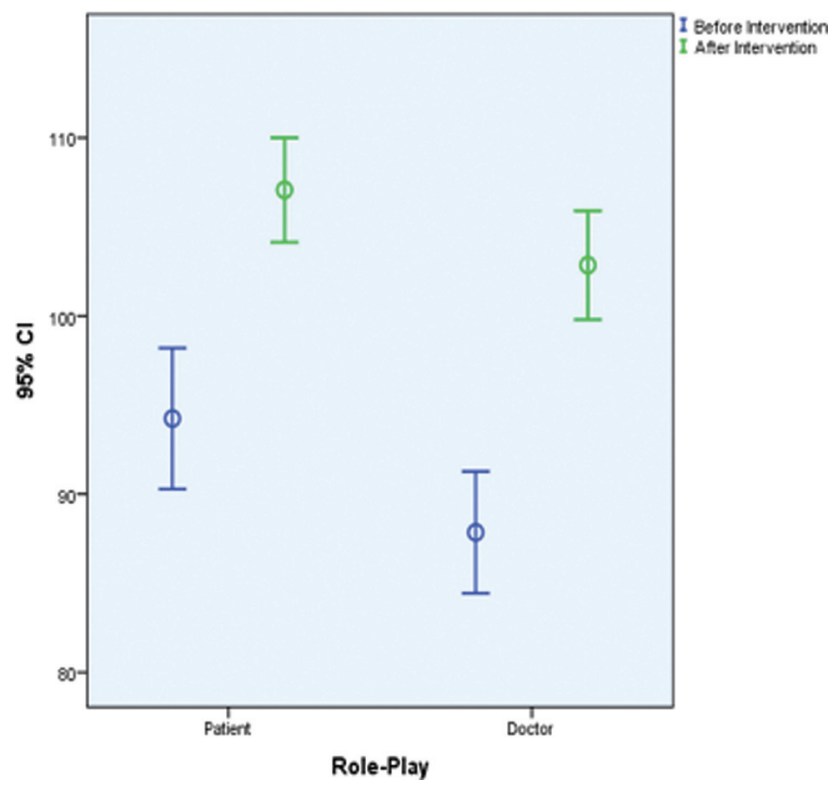

Fig. 3 Error plot showing the difference in the improvement in performance in both patient and doctors group after the intervention.

Table 3 Comparison of communication skill scores among patients' perception and doctors' perception before and after intervention

\begin{tabular}{|c|c|c|c|c|c|}
\hline & Roleplay & $n$ & Mean rank & Z & $p$-Value \\
\hline \multirow[t]{2}{*}{ Before Intervention } & Patient & 68 & 77.36 & \multirow[t]{2}{*}{-2.483} & \multirow[t]{2}{*}{$0.013^{a}$} \\
\hline & Doctor & 68 & 60.52 & & \\
\hline \multirow[t]{2}{*}{ After Intervention } & Patient & 68 & 75.63 & \multirow[t]{2}{*}{-1.97} & \multirow[t]{2}{*}{0.05} \\
\hline & Doctor & 68 & 62.27 & & \\
\hline
\end{tabular}

${ }^{\text {a }}$ Statistical significance set at 0.05 (Mann-Whitney $\mathrm{U}$ test).

Table 4 Student feedback on the session

\begin{tabular}{|l|l|l|l|l|l|l|}
\hline I. Short lecture on “doctor-patient communication" & $\begin{array}{l}\text { Strongly } \\
\text { agree }\end{array}$ & Agree & $\begin{array}{l}\text { No } \\
\text { comments }\end{array}$ & Disagree & $\begin{array}{l}\text { Strongly } \\
\text { disagree }\end{array}$ \\
\hline 1 & Questions & It helped in understanding the need for communication & $38 \%$ & $62 \%$ & - & - \\
\hline 2 & $\begin{array}{l}\text { It helped in the participation in the "prescription } \\
\text { module activity" }\end{array}$ & $27 \%$ & $68.3 \%$ & $5.6 \%$ & - & - \\
\hline 3 & $\begin{array}{l}\text { There is a need for communication classes in } \\
\text { prescription practical class }\end{array}$ & $35 \%$ & $54 \%$ & $9.5 \%$ & $2.4 \%$ & - \\
\hline 4 & Various aspects of communication skills were highlighted & $35 \%$ & $61.1 \%$ & $3.2 \%$ & - & - \\
\hline 5 & It helped in active learning of the communication skill & $40.5 \%$ & $55 \%$ & $4.8 \%$ & - & - \\
\hline II. Roleplay demonstration & It made the session interesting & $45.2 \%$ & $48.4 \%$ & $4.8 \%$ & $1.6 \%$ & - \\
\hline 6 & I learned the aspects which could not have been learned in & $35.7 \%$ & $56.3 \%$ & $7.1 \%$ & $0.8 \%$ & - \\
\hline 7 & didactic lecture class on prescription & & & - \\
\hline 8 & This kind of session will help in the future practice & $48.4 \%$ & $44.4 \%$ & $7.1 \%$ & - & - \\
\hline 9 & This should be part of prescription classes in future & $42.1 \%$ & $44.4 \%$ & $12 \%$ & $1.6 \%$ & - \\
\hline
\end{tabular}


interaction, small group learning, video recording and review, and rehearsal. ${ }^{18}$ Roleplay is a powerful tool to make students learn communication skills, in order to deal with realistic clinical situations that require counselling or communication. Roleplay in a simulated scenario gives students a chance to develop their affective domain. It can also be used as an opportunity for feedback and correction of their errors. Good communication skills can be taught to undergraduates through roleplay ${ }^{19}$ Our study observed that roleplay video demonstration showed a significant difference in postactivity scores in both patient and doctor groups compared with preactivity scores. On analyzing the different components of the Kalamazoo consensus statements, all the components have showed significant improvement in postactivity scores compared with preactivity scores. Many other studies have also confirmed wherein roleplay showed effectiveness in teaching communication skills. ${ }^{20-22}$

The study involved two components, consisting of a small lecture followed by practical activity, as substantiated by the recent systematic review; Berkoff et al identified that a combination of didactic and practical components appeared to have the most significant positive impact on communication skills' improvement. ${ }^{23}$ In the present study, we evaluated the difference between the doctors' perception (self-evaluation) versus patients' perception (peer evaluation) on the doctor's communication skills. It showed that before roleplay video demonstration, there was a significant difference among the assessment scores between the groups, indicating the lack of awareness on different communication elements and increased confidence in the simulated doctors' group on their performance compared with the simulated patients' perception. However, once the roleplay video demonstration was done, the postactivity score did not show any significant difference. Simulated patients provide a safe, low-anxiety learning experience where students could learn from feedback and build competence and confidence. ${ }^{11}$ Manzoor et al recommended that by involving students in roleplays, the components of both cognitive and affective domains of medical education can be delivered. ${ }^{24}$ Other authors also have emphasized the importance of roleplay in medical education. ${ }^{22,25}$ As discussed in the review by Modi et al, roleplays can provide an opportunity for rehearsal, improvisation, and even teaching of complex case scenarios. One of the drawbacks of roleplay methodology can be acting out, especially since students are not actors. It is not easy for them to come out of the "doctor" character to be a "patient." 26 This drawback was addressed, as the study involved showing a roleplay video enacted by the trained faculty to help them rectify the lacunae in their preactivity and improve in the postactivity.

The overall feedback about the activity taken in two separate components revealed that the first section of the small lecture helped to understand the need for communication in general and in practical prescription classes. Students opined that it helped to participate in the "prescription module activity along with active learning of the communication skill."
The second component of roleplay demonstration made the session enjoyable. It made them learn the aspects that could not have been learned in didactic lecture class on prescription; students also felt the need for this kind of session to help them in future practice. This was very similar to the findings of the recently done study by Nair, where the students' perception about roleplay in teaching communication skills was evaluated. ${ }^{27}$ This study differed from Stevenson and Sander, ${ }^{28}$ where the majority of the students had a negative perception about roleplay.

The teaching by showing such video demonstrations enacted by trained faculty can be one way in the present situation of academics, where students are missing the opportunity to interact with patients frequently. This kind of module can be helpful to complement the attitude, ethics and communication (AETCOM) module, which is being implemented in the competency-based medical education (CBME) curriculum. Further, the faculty can come up with well-scripted clinical interviewing of different case scenarios, which can be used as teaching-learning media for subsequent batches of students.

\section{Limitations}

In our study, students suggested to include more scenarios in future sessions, as we included only one scenario; this was one of the limitations. There is a need for attention and feedback to the student at the individual level, which can be improved in future sessions by involving more facilitators with adequate preplanning. For effective roleplay sessions, the educators' role is to help the learners to set the goals and know when and how to provide feedback to the learners to deepen skills and promote self-awareness. Humphrey et al opined that some medical students reported a feeling of being harassed by all the attention and comparison of their professional and unprofessional behaviors by the medical faculty to discipline the students rather than educate them. ${ }^{29}$ The challenge is to create an environment that does not cause too much anxiety for the learner, as suggested by Jackson et al. ${ }^{30}$

The other limitation could be a single-step evaluation conducted in our study, which is little difficult to assess the long-term impact of intervention. As suggested by the Ottawa consensus group, one type of assessment will not be sufficient and valuable in evaluation; multiple kinds of measures by multiple observers synthesized over time with data gathered in multiple, complex, and challenging contexts will be useful. ${ }^{31}$ Other limitations could be the lack of long-term impact of roleplay sessions in bringing around behavioral change, which may be assessed by conducting the same session with the involvement of an actual patient at a future point of time during the course.

\section{Conclusion}

Roleplay video demonstration and lecture class on essential component of communication has positively impacted communication skills in undergraduate students. It offers a 
realistic basis for the use of roleplay in undergraduate students to acquire communication skills. Standardized doctor-patient case scenarios will provide us the opportunity for such direct evaluation of trainees. A similar kind of teaching of communication skills using roleplay video method holds promise when adopted at clinical settings also.

\section{Conflict of Interest}

None declared.

\section{Acknowledgment}

We would like to acknowledge the help of Dr. Manohar Bhat for analyzing the data.

\section{References}

1 Crisp AH. Undergraduate training for communication in medical practice. J R Soc Med 1986;79(10):568-574

2 Stewart MA. Effective physician-patient communication and health outcomes: a review. CMAJ 1995;152(09):1423-1433

3 Kaufman DM, Laidlaw TA, Macleod H. Communication skills in medical school: exposure, confidence, and performance. Acad Med 2000;75(10, Suppl):S90-S92

4 Seshadri KG. Communication skills. In: Bhuiyan PS, Rege NN, Supe A, eds. The Art of Teaching Medical Students. 3rd ed. New Delhi: Reed Elsevier India Pvt. Ltd; 2015:226-235

5 Rao JK, Anderson LA, Inui TS, Frankel RM. Communication interventions make a difference in conversations between physicians and patients: a systematic review of the evidence. Med Care 2007; 45(04):340-349

6 Travaline JM, Ruchinskas R, D’Alonzo GE Jr. Patient-physician communication: why and how. J Am Osteopath Assoc 2005;105 (01):13-18

7 Chhatwal J. Creating a demand for communication skills training in India. Med Educ 2009;43(05):478

8 Chatterjee S, Choudhury N. Medical communication skills training in the Indian setting: Need of the hour. Asian J Transfus Sci 2011;5(01):8-10

9 Supe A. Graduate Medical education regulation 2019: competency-driven contextual curriculum. Natl Med J India 2019;32(05): 257-261

10 Levinson W, Pizzo PA. Patient-physician communication: it's about time. JAMA 2011;305(17):1802-1803

11 Bokken L, Rethans JJ, Scherpbier AJ, van der Vleuten CP. Strengths and weaknesses of simulated and real patients in the teaching of skills to medical students: a review. Simul Healthc 2008;3(03): 161-169

12 Makoul G. Essential elements of communication in medical encounters: the Kalamazoo consensus statement. Acad Med 2001;76(04):390-393

13 Likert R. A technique for the measurement of attitudes. Arch Psychol 1932;140:1-55
14 Centor RM. To be a great physician, you must understand the whole story. MedGenMed 2007;9(01):59

15 McKinstry B, Ashcroft RE, Car J, Freeman GK, Sheikh A. Interventions for improving patients' trust in doctors and groups of doctors. Cochrane Database Syst Rev 2006;19(03):CD004134

16 Berengere DN, Lori DB, Orlando H, Julia R, Debra R. Improving Interpersonal Communication Between Health Care Providers and Clients: Quality Assurance Methodology Refinements Series. Bethesda, MD: Quality Assurance Project; 1997

17 Kourkouta L, Papathanasiou IV. Communication in nursing practice. Mater Sociomed 2014;26(01):65-67

18 Silverman J. Teaching clinical communication: a mainstream activity or just a minority sport? Patient Educ Couns 2009;76 (03):361-367

19 Mogra I. Roleplay in teacher education: is there still a place for it? Teach Educ Adv Netw J 2012;4:4-15

20 Nikendei C, Kraus B, Schrauth M, et al. Integration of role-playing into technical skills training: a randomized controlled trial. Med Teach 2007;29(09):956-960

21 Bosse HM, Nickel M, Huwendiek S, Jünger J, Schultz JH, Nikendei C. Peer role-play and standardised patients in communication training: a comparative study on the student perspective on acceptability, realism, and perceived effect. BMC Med Educ 2010;10:27

22 Deveugele M, Derese A, De Maesschalck S, Willems S, Van Driel M, De Maeseneer J. Teaching communication skills to medical students, a challenge in the curriculum? Patient Educ Couns 2005;58 (03):265-270

23 Berkhof M, van Rijssen HJ, Schellart AJ, Anema JR, van der Beek AJ. Effective training strategies for teaching communication skills to physicians: an overview of systematic reviews. Patient Educ Couns 2011;84(02):152-162

24 Manzoor I, Mukhtar F, Hashmi NR. Medical students' perspective about role-plays as a teaching strategy in community medicine. J Coll Physicians Surg Pak 2012;22(04):222-225

25 Wearne S. Role play and medical education. Aust Fam Physician 2004;33(10):858

26 Modi JN, Anshu,Chhatwal J, Gupta P, Singh T. Teaching and assessing communication skills in medical undergraduate training. Indian Pediatr 2016;53(06):497-504

27 Nair BT. Role play - An effective tool to teach communication skills in pediatrics to medical undergraduates. J Educ Health Promot 2019;8:18

28 Stevenson K, Sander P. Medical students are from Mars-business and psychology students are from Venus- University teachers are from Pluto? Med Teach 2002;24(01):27-31

29 Humphrey HJ, Smith K, Reddy S, Scott D, Madara JL, Arora VM. Promoting an environment of professionalism: the University of Chicago “Roadmap". Acad Med 2007;82(11):1098-1107

30 Jackson VA, Back AL. Teaching communication skills using roleplay: an experience-based guide for educators. J Palliat Med 2011; 14(06):775-780

31 Hodges BD, Ginsburg S, Cruess R, et al. Assessment of professionalism: recommendations from the Ottawa 2010 Conference. Med Teach 2011;33(05):354-363 